\title{
The Computer Assisted Instruction Model Based on a Combination of Tutorial Model and Drill and Practice Model in the Instructional Design of Database Systems in Information Technology Colleges
}

\author{
Ruliah $^{1,2, *}$, Zulfiati Syahrial ${ }^{1}$, Hartati Muchtar ${ }^{1}$ \\ ${ }^{1}$ State University of Jakarta, Indonesia \\ ${ }^{2}$ STMIK Banjarbaru, Indonesia
}

Received July 9, 2019; Revised September 9, 2019; Accepted September 16, 2019

Copyright@2019 by authors, all rights reserved. Authors agree that this article remains permanently open access under the terms of the Creative Commons Attribution License 4.0 International License

\begin{abstract}
The traditional face-to-face teaching methods in the class that emphasize teaching-centered learning systems caused teachers to be unable to deliver teaching material thoroughly because of the limited time. The Computer Assisted Instruction (CAI) model presents learning by using a variety of media, both in the form of text, images, and in the way of interactive videos, so that it helps the learning process effectively and helps students to set the pace of learning independently anytime and anywhere. Interconnection of the CAI model with online-based technology also helps students improve their learning creativity, because diverse learning resources support it. This paper presents CAI conceptual models based on a combination of Tutorial models and Drill and Practice models, which are supported by online technology to provide conceptual understanding at the beginning of learning and offer exercises to develop creativity and test students' abilities in the final stages of learning Database Systems. The evaluation results on limited trials show that the CAI model design based on a combination of Tutorial models and Drill and Practice models much motivates students to learn and improve mastery of competencies in the Database System. Another finding in this paper is the need to provide adequate guidance for the application of CAI in its use, and the obligation to provide more effective designs when CAI applications are designed to connect to systems that offer to teach resources online, so students really can use CAI as an auxiliary media active learning for independent learning.
\end{abstract}

Keywords Interactive Learning Media, Computer Assisted Instruction, Drill and Practice, Tutorial, Database System

\section{Introduction}

Information System is the process of collecting data that is processed into information that is useful for the users (Hasan, Shamsuddin, and Aziati, 2013). The information generated becomes the basis of policy considerations. Ward and Prepard suggest that there are three main goals of the application of Information Systems in an organization. These three things are improving work efficiency by automating various processes that manage information, improve management effectiveness by satisfying information needs for decision making, and improve competitiveness to improve the organization's competitive advantage by changing the style and way of doing business (Setiawan, Ilman, 2012). Al-Mamary, Shamsuddin \& Aziati (2014)) stated the same thing that Information Systems aims to provide accurate, relevant, and complete information to managers to improve organizational performance. In its application, the ability of a company to gain a competitive advantage is determined by how the information system is managed and used correctly so as to improve service and reduce operational costs (Ramaya, Omar, 2010), increase company productivity (Oliveira, Martins, 2011), improve team performance (Choi, Lee \& Yoo, 2010), and make it easier for management to make effective decisions (Rabren, 2010).

One crucial part of the Information System is the Database System. The database is the principal strategic part of Information Systems to support management in making decisions (Piattini, Diaz, 200). The database 
system provides a flexible means of access, protects data from damage, and avoids illegal use. The database system provides a mechanism for shared use such as data connectivity to minimize data pooling, maintain data integrity, and eliminate data dependence on application programs. The database system also standardizes the definition of data elements (Elmasri, Navathe, 2016).

Effectiveness, The design of a database system that is a constituent element of an information system significantly, influences the success of the information system. A useful database system design makes it easier to reuse the data contained in the database system, thereby increasing the quality of the information system. When an organization needs a new application, and at the same time the design of its database system is available properly, then the system developer (programmer) only needs to make the interface required by the user to connect to the open database system. For this to work, the design of a database system must be well prepared to support future system development. Therefore it is essential to offer a useful database system to support data access requests for users or other systems. Knowledge of the database system is needed by everyone who wants to take part in the development of information system technology.

Studying in the field of informatics is one way to gain knowledge about database systems. The Joint Task Force on Computing Curricula Association for Computing Machinery (ACM) and IEEE Computer Society in 2013 put Database Systems as one of the study areas for Undergraduate Degree Programs in Computer Science (IEEE Computer Society, 2013). The Australian National University using the ACM-IEEE Computer Science Curriculum in 2015 also places database systems as one area of study (Milthorpe, 2017). Schildkamp, Lai, and Earl, (2013) suggested that the database system received a lot of attention in the field of education, especially in the Computer Science program.

We conducted a preliminary study on the Information Systems Department of STMIK Banjarbaru, one of the Higher Education Information Technology Institutions in Indonesia which contains a Database System in its teaching curriculum. Higher education uses traditional face-to-face teaching methods in classrooms that emphasize teaching-centered learning systems. We conducted a study using questionnaires aimed at teachers and students, as well as making direct observations in the class that held Database Systems lectures. The results of our research show that direct teacher-centered teaching methods in the database system lectures cause the learning process to be passive, students' understanding is not optimal in certain parts of competence, and the atmosphere of learning in the classroom is boring. Some students seem to need special attention and handling at the time of learning, but cannot be handled by the teacher because there is not enough time to do direct assistance. This condition is in line with the findings of Simarmata et al. (2018) which suggest that teachers face difficulties in conveying all the material in conventional learning because of the limited time allocation, consequently lagging students follow learning, and cause students unable to reach the minimum competency standards planned in the learning design.

Using a student-centered learning model allows teachers to make time to correct specific student problems, consult with students individually, and teach one by one in small groups. The use of learning technology can help alleviate the work of the teacher, helping them become creative classroom managers, rather than just as information dividers. Idris, Ali, Rajuddin \& Muhammad (2012) stated that teaching and learning strategies that focus on students make students active, creative, and focus on exposing various problems and challenges.

One learning model that utilizes student-centered learning technology is Computer Based Learning. Computer-based learning is an interactive learning approach in which computers replace the role of an instructor. Computer-based learning provides instruction, tests, and student learning feedback independently, with very little or no teacher involvement (Darmawan, 2011). Computer Assisted Instruction (CAI) is a form of computer-based learning that uses models of tutorials, exercises and practices, simulations, and problem-solving approaches to present topics, and test students' understanding. These programs allow students to study material at their own pace.

The teaching system has tested many of the uses of the CAI model. Widayanti examined the use of CAI in the Class X Operating System subjects at Vocational High Schools in Indonesia. The study showed students' responses to learning media amounted to $73.75 \%$ included in the good category, and students' learning outcomes were at an average of 82.00 in the post-test (Widayanti, 2016). Suleman, Hussain, Din, and Iqbal (2017) tested the effect of CAI on the teaching of high school students' physics. They found that CAI-based teaching had a significant positive effect on students' academic achievement and retention in Physics, and recommended the use of computer-assisted teaching techniques for science teachers. Previously Rahman, Ismail, and Nasir (2014) have also tested the effect of CAI on teaching Physics (Movement and Vector Analysis) for high school students. Their findings indicate that there is an increase in learning motivation and students' conceptual understanding of learning using interactive software media.

This paper presents the concept of interactive CAI-based learning technology using a combination of tutorial models and drills and practice models on learning Database Systems in the Information Systems Department of STMIK Banjarbaru.

\section{Literature Review}

In recent times, learning database systems have used 
several methods.

Demour (2010) proposed a Cognitive Training-based approach to teaching Relational Database Design and Analysis. This approach divides the stages of learning into three main phases. In the initial stage, breaking down the database design process into manageable phases then sets the completion and completion procedures. The pedagogical process continues by introducing students to the theoretical basis of each step they follow, by introducing practical examples of that phase. Next, divide students into groups in class and give assignments in the form of small problems to them. One of the requirements of the course is the delivery of real-life issues that represent students' understanding of the concept of the course. Students work on these projects in groups outside the class that have different members than those in the class. The results of the achievements in the experiment show that this approach is practical, easy to implement, increases student motivation, and can achieve a higher level of learning.

Learning Database Systems supported by eLearning were introduced by Paulova, Tesarova, and Manenova (2010) at the Faculty of Management and Information, University of Hradec Kralove. The subject of observation is students' performance in the cognitive field (memory, understanding, and application of acquired knowledge). Learning outcomes of Database Systems supported by well-designed and appropriately implemented eLearning are comparable to the results achieved by students from traditional face-to-face lessons.

Yuelan at al. (2011) proposed combining various methods in learning database systems. First, the use of multimedia technology to simulate the processes and effects of database systems can motivate students to increase the efficiency and quality of teaching. Second, a project-based approach based on constructivist learning theory has an impact on students to be more familiar with system operations, so they can concentrate on the main objectives of database studies without having to spend a lot of time analyzing business processes. Third, applying an experimental model of teaching in trials. Combining theory with practice will help students master basic theoretical knowledge, enable students to learn scientific knowledge, and foster independent learning skills and motivate their enthusiasm for learning. The concept of using various methods allows students to train the use of integrated experience to solve practical problems and create thinking skills.

Mason (2013) introduced a practicum-based learning model on the teaching of Database Administration at Regis University College for Professional Studies (CPS). Regis database practice encourages the development of soft skills by allowing students to volunteer in leadership roles, such as Project Managers, Technical Leaders and Project Leaders. Students improve communication skills by working on software development projects in real life. Students create and maintain databases used for all undergraduate and graduate database programs in CPS. The results of the learning evaluation indicate that the Regis database practicum is a successful experience that helps students perfect their technical skills and to develop new soft skills. This Regis database learning model aims to inspire students to continue to study the subject of database technology after they graduate.

Hilles (2017) proposed the teaching of Database Systems using interactive learning media based on computer. They gave the name "MDB," a Knowledge-Based Smart Learning System. The purpose of building MDB is as an education system using author tools. The MDB system observes student actions and adapts to their knowledge and learning abilities. MDB's intelligent tutoring system helps students understand, build, and use databases. MDB's thoughtful guidance divides teaching materials into lessons, examples, tiered exercises, and examinations.

We propose the concept of learning based on Computer Assisted Instruction (CAI) using a combination of Tutorial model and Drill and Practice model on learning Database Systems in the Information Systems Department of STMIK Banjarbaru - Indonesia. The CAI model based on a combination of Tutorials and Drill \& Practice provides conceptual understanding at the beginning of learning and offers unstructured exercises to develop creativity and test students' abilities in the final stages of learning. This model also offers interconnection facilities to online systems that offer resources to enrich students' insights in developing learning concepts, so that they can truly become effective assistive media for independent learning.

\section{Methodology}

In this work, the Research and Development (R \& D) method is used to develop CAI-based interactive learning designs. R \& $\mathrm{D}$ is a method used to build and test the effectiveness of a product. We use the Research and Development (R \& D) research model proposed by Gall, Gall, and Borg (2015) in the initial stages of research, then follow the scenes in the model of development of learning design proposed by Dick, Carey, and Carey (2015) as recommended by Gall and Borg. The research steps consist of:

1. Analysis of problems and system requirements. The Focus Group Discussion (FGD) method was used to formulate the competencies needed in the Database System learning design. The FGD involves instructional designers, heads of study programs in universities, college graduates, and college graduates.

2. Development of learning design using the Dick \& Carey development model. The stages of development consist of (1) identifying general instructional objectives, (2) conducting instructional 
analysis, (3) identifying behavior and initial characteristics of students, (4) writing specific instructional goals, (5) developing assessment instruments, (6) developing strategies learning, and (7) developing instructional materials. The seventh stage of developing learning design (developing learning materials) is the stage for implementing the CAI Concept based on a combination of Tutorial models and Drill and Practice models.

3. The formative evaluation process of learning design uses the Dick \& Carey model. Developmental evaluation stages consist of (1) expert validation (instructional design experts, content experts, and media experts / Information Technology), (2) one-on-one evaluation by students. At the end of each phase of the trial, data analysis and product revisions are made based on input obtained from each evaluation/trial stage.

4. Test the effectiveness of the instructional design. The effectiveness of the model is tested using pseudo-effectiveness tests, namely testing the model in conditions that resemble actual conditions. Assessment of model effectiveness was carried out in small group trials. Nine students who have characteristics of the high, medium and low ability become respondents at the trial stage. The model effectiveness test stage consists of:

1) Conduct an initial test to determine the students' initial competencies by referring to the learning objectives

2) Explain to students the purpose of the evaluation, and explain the learning activities carried out, and encourage students to comment freely at all times during the evaluation activities.

3) Carry out learning activities by sharing with each student a CAI-based learning application (valid and perfect based on the results of expert evaluation) to be used.

4) Carry out the final test using a test that is equivalent to the test used in the initial analysis

5) Share questionnaires to get students' assessment of the quality of the design of CAI produced

6) Conduct interviews with several students to gain more in-depth ratings and comments about the quality of CAI products, which include:

- How easily learners understand the lesson using CAI products

- How systematic and exciting is the use of CAI products

- Which part of the experience is challenging to understand and why
- Conformity of planned time in the design of learning with the time used to study and master the material.

- How effective illustrations/ graphics/ graphics/ videos help to understand the material

- Compatibility of material with test items (relevance and level of difficulty)

7) Using the results of a small group evaluation to revise the CAI product design, until the competency mastery test results reach the required minimum standards.

\section{Results and Findings}

\subsection{Proposed CAI Concept}

Database System Topics generally consist of two programs. The first part is logical analysis and design, consisting of Requirements Specification and Requirements Analysis, Data Modeling, Relational Mapping, and Normalization. The second part is the physical design and implementation with the Data Base Management System, consisting of SQL: Data Definition Language, SQL: Data Manipulation Language. The concept of needs analysis and requirement specifications is a program that is oriented to user needs so that the scope of the study is unstructured problems. The design and implementation must follow the needs analysis and requirements specifications. The characteristics of the database system course require the use of learning methods not only to emphasize conceptual understanding but also to practice in-depth exploration of unstructured cases.

Tutorial models in CAI based Tutorial (Lestari, 2015; Seow, Pan, 2017) are learning strategies developed for material that has characteristics: new information, conceptual nature, and emphasizes the optimization of achievement of cognitive aspects. The Drill model as in (Pacol, Patacsil, 2018; Pujawan, 2018) provides learning experiences through the creation of imitations of forms of expertise that approach the real atmosphere through the provision of exercises to develop creativity and test students' abilities (Darmawan, 2011). The characteristics possessed by the Tutorial model and Drill model are in line with the learning characteristics of database systems that require learning concepts that emphasize conceptual understanding and require deep practice to expose unstructured cases. Our paper proposes a CAI model based on a combination of Tutorial and Drill and Practice models for learning database systems, as shown in Figure 1. 


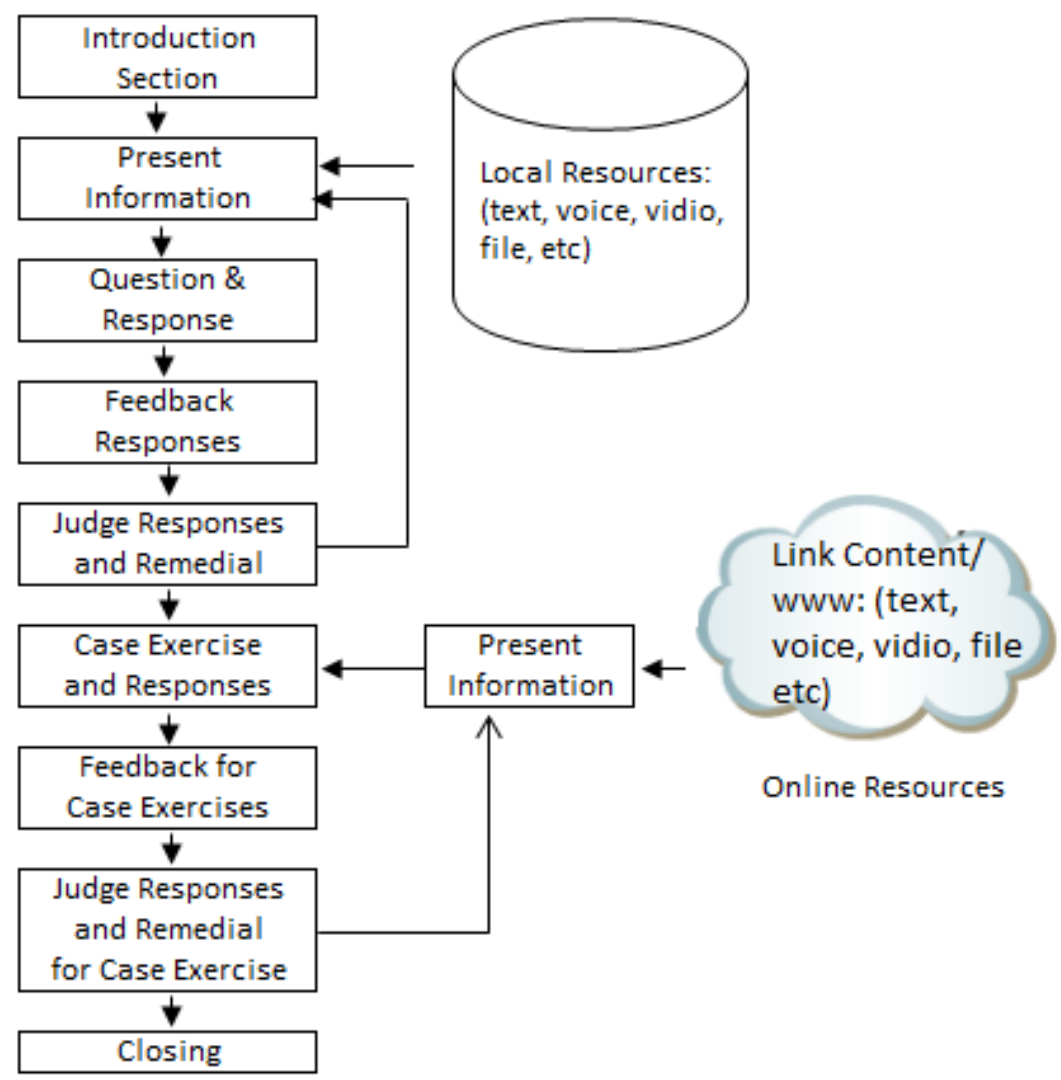

Picture 1. CAI-Based Procedural Model of Combination Tutorial and Drill \& Practice

The CAI model in Figure 1 runs on a Web-based platform or a CMS (Content Management System) application such as e-Learning. The system is used to help students learn independently anytime and anywhere, and also in classroom teaching with teacher's assistance. The CAI procedure based on the combination of the proposed Tutorial and Drill \& Practice consists of 9 steps as follows:

1. Introduction Section. The CAI system displays instructions or learning steps.

2. Present Information. The CAI system presents material sourced from the CAI system's local resource applications in the form of tutorial scripts. Presentation of information in the form of visual information other than text such as images, graphics, photos, and images /videos.

3. Question and Response. The CAI system presents issues and assesses the extent to which students can remember and understand the lessons offered. This stage is an integrated evaluation stage in the material presentation stage.

4. Feedback Response. The CAI system provides feedback as a reaction to the responses given by students. The feedback function is to inform whether the answer given by the student is right or not. Input in the form of messages in the form of text and graphic illustration forms. If the response given by students is correct, the program reinforces students. But if the student's answer is wrong, the program provides a sentence with a statement that the response given is incorrect.

5. Judge Response and Remedial. The CAI system evaluates students' answers/responses so they can provide feedback for students. Assessment functions to assess students' learning outcomes and make a decision whether the learning process can be continued to the next stage or repeated. Repetition takes the form of restatement of material that students have seen, sourced from local resources.

6. Case Exercise and Response. The CAI system presents questions in the form of new case studies, but is still relevant to the materials that have been studied / seen by students, and assesses the extent to which students are able to develop certain material they have acquired. Students can reach this session if they have gone through and mastered perfectly all the main material of learning.

7. Feedback for Case Exercise. The CAI system provides feedback as a reaction to students' responses (as in step number 4)

8. Judge Response and Remedial for Case Exercise. The CAI system evaluates students' 
answers/responses so they can offer feedback to students. Assessment functions to evaluate the results of case training and decide whether the learning process can continue to the next stage or return to its first stage. Repetition in the form of presentation of enrichment material sourced from online resources/internet (www, download files, You Tube, etc.) to enrich students' insight before doing the case rehearsal. This concept can train students to think critically and develop ideas into available material.

9. Closing. The CAI system presents a summary of information about lessons in the form of the main points of a paragraph about learning objectives and provides recommendations for further learning.

The first step to the fifth step is the underlying logical structure of the Tutorial-based CAI model, while the sixth step to the eighth step is the core of the Drill and Practice-based CAI model. Both of these models are integrated resulting in learning logic procedures in the form of applying the Tutorial system at the beginning of teaching to provide conceptual understanding for students and at the end of the teaching offering exercises to develop creativity and test students' abilities.

\subsection{Assessing the Effectiveness of the CAI Model}

The assessment of the effectiveness of the CAI model in Figure 1 takes place at the stage of the formative test of small group students (nine students who have characteristics of high, medium, and low ability) according to the procedure of research methodology. Evaluation results are as in table 1 in table 1 :

Table 1. Effectiveness Test Results for the CAI Model Application

\begin{tabular}{|c|c|c|l|}
\hline Experiment & $\begin{array}{c}\text { Pretest } \\
\text { Completeness } \\
\text { Average (\%) }\end{array}$ & $\begin{array}{c}\text { Posttest } \\
\text { Completeness } \\
\text { Average (\%) }\end{array}$ & $\begin{array}{c}\text { General (major) } \\
\text { Evaluation Results }\end{array}$ \\
\hline \multirow{2}{*}{ I } & 21,2 & $\begin{array}{l}\text { There are several paragraphs in the learning material that are not clear in the meaning } \\
\text { of the sentence } \\
\text { Students need explanatory help when students encounter obstacles in understanding } \\
\text { teaching materials } \\
\text { Need to complete learning materials need to be with adequate case examples } \\
\text { Students are very motivated by the learning and training scenario models offered in the } \\
\text { application, but the completion time of one learning session feels too long so that there } \\
\text { is a feeling of boredom in the final stages of learning } \\
\text { Illustrations in the form of images still need to be presented more interesting } \\
\text { time used to study and master a particular competency beyond the time planned in the } \\
\text { learning design }\end{array}$ \\
\hline \multirow{2}{*}{ II } & 90,7 & $\begin{array}{l}\text { Students still need explanatory help when students encounter obstacles in } \\
\text { understanding teaching materials } \\
\text { Time used to study and master a particular competency beyond the time planned in the } \\
\text { learning design } \\
\text { The completion time of one learning session feels too long to cause boredom in the } \\
\text { final stages of learning } \\
\text { Instructions for using the application are unclear so that it requires assistance at the } \\
\text { beginning of the application }\end{array}$ \\
\hline
\end{tabular}


Based on the results of the effectiveness test of using the CAI application based on a combination of Tutorial models and Drill \& Practice models as in table 1, we discussed some essential findings as follows:

First: There are eight of the nine respondents in the first and seventh stages in the second stage test stated that the learning and training scenario models offered in the CAI algorithm hugely motivated students in learning and training. The percentage of learning completeness that reaches $90 \%$ supports this statement. This finding is also consistent with the results of Thomas et al. (2013) and Suleman et al. (2017) which concluded that CAI-based learning could motivate and improve students' achievement. However, the other side of success is that respondents generally feel that they are bored in the final stages of knowledge because the process of completing a learning session is too long. The average time spent perfecting a teaching session exceeds the time set in the learning plan, even though the learning material is pure. Respondents suggested that the use of this CAI model is only in the learning conditions outside the classroom, which sets a long period in completing one learning session so that there is an opportunity for students to take a break in the middle of learning activities when they feel bored. This finding is identical to Chaudhari's (2013) results that CAI is a new instructional strategy in effective teaching.

Second: Although the scenarios in the CAI algorithm design can motivate students to learn independently, some students are indicated to have difficulty following certain parts of the Database System material, especially those related to modeling material. Most of the students stated that they still needed instructors (assistants) to get a more in-depth explanation when they had difficulty understanding certain parts of the learning material. On this basis, the interactive CAI feature that is connected to the online resources system (internet) still needs further attention (in terms of design effectiveness) so that online resources systems can play a maximum role as a useful companion that offers assistance to students in the learning and training process, as in the findings of Longmuir (2014). Another solution expected by respondents is the interconnection of interactive CAI models based on Tutorials and Drill with a Web-based communication system that connects students with instructors interactively.

Third: The need to complete this CAI design with instructions for use and other adequate instructions relating to learning and practice. However, the idea underlying the emergence of this interactive CAI design is that students can use it as a medium of learning independently by minimizing direct assistance or instructor's involvement in learning sessions.

The availability of online-based technology now makes it possible to design CAI models based on Tutorials and Drill that allow students to more easily interact with instructors and diverse learning resources when students have difficulty learning under self-control using interactive learning media.

\section{Conclusions}

The CAI model design based on a combination of Tutorial and Drill and Practice models much motivates students to learn under self-control, to improve mastery of competencies in the Database System. However, it is necessary to provide adequate guidance on the CAI application in its use. A more useful design model is also needed if the CAI application is intended to connect to systems that provide online teaching resources. This suggestion is to be the focus of further studies so that students can use CAI as an effective interactive learning media for learning.

\section{REFERENCES}

[1] Al-Mamary, Y. H., Shamsuddin, A., \& Aziati, N. (2014). Factors affecting the successful adoption of management information systems in organizations towards enhancing organizational performance. American Journal of Systems and Software, 2(5), 121-126.

[2] Chaudhari, P. (2013). Computer Assisted Instruction (CAI): Development of instructional Strategy for Biology Teaching. UGC-JRF, 2(1), 106-116

[3] Choi, S. Y., Lee, H., \& Yoo, Y. (2010). The Impact of Information Technology and Transactive Memory Systems on Knowledge Sharing, Application, and Team Performance: A Field Study. MIS Quarterly, 34(4), 855-870.

[4] Darmawan, D. (2011). Teknologi Pembelajaran. Bandung: Rosada Karya

[5] Dick, W., Carey, L., Carey, J.O. (2015). The Systematic Design of Instruction, Eight Edition. USA: Pearson.

[6] Dmour, A. A. (2010). Propose A Cognitive Apprenticeship Approach For Teaching An Analisis Dan Desain Database Relational Course. Journal of Information \& Computational Science, 7(12), 2495-2502.

[7] Elmasri E., Navathe S.B. (2016). Database Sistem, Seventh Edition, USA: Pearson.

[8] Gall, M.D., Gall, J.P., Borg, W.R. (2015). Applying Educational Research, Seventh Edition. USA: Pearson

[9] Hasan, Y., Shamsuddin, A., \& Aziati, N. (2013). The impact of management information systems adoption in managerial decision making: A review. The International Scientific Journal of Management Information Systems, 8(4), 010-017.

[10] Hilles, M. M., \& Naser, S. S. A. (2017). Knowledge-based Intelligent Tutoring System for Teaching Mongo Database. European Academic Research, 4(10), 8783-8794

[11] Idris, A., \& Rajuddin, M. (2012). The trend of engineering education in Nigerian tertiary institutions of learning 
towards achieving technological development. Procedia-Social and Behavioral Sciences, 56, 730-736.

[12] IEEE Computer Society (2013, December, 20). Computer Science Curricula 2013: Curriculum Guidelines for Undergraduate Degree Programs in Computer Science, The Joint Task Force on Computing Curricula, Association for Computing Machinery.

[13] Lestari, A. S. (2015). Application of Computer Based Learning Model Tutorial as Medium of Learning. American Journal of Educational Research, 3(6), 702-706.

[14] Longmuir, K. J. (2014). Interactive computer-assisted instruction in acid-base physiology for mobile computing platforms. Advances in physiology education, 38(1), 34-41.

[15] Mason, R. (2013, July). A Database Practicum for Teaching Database Administration and Software Development at Regis University. In Proceedings of the Informing Science and Information Technology Education Conference, (159-168).

[16] Milthorpe, J. (2017). ACM-IEEE Computer Science Curriculum 2015 Structured, Australian National University, https://cs.anu.edu.au/courses/comp1110/ acmcc/, accessed 10-4-2019

[17] Oliveira, T., \& Martins, M. F. (2011). Literature Review of Information Technology Adoption Models at Firm Level. Electronic Journal of Information Systems Evaluation, 14(1), 110-121.

[18] Pacol, C. A., \& Patacsil, F. (2017). Drill and practice courseware in its fundamentals. PSU Journal of Engineering, Technology, and Computing Sciences, 1(1), 33-47.

[19] Poulová, P., Tesarova, B., \& Maneonova, M. (2010, July). Efficiency comparison of eLearning supported instruction to traditional university courses in the subject of database systems 2. In EDUCATION'10 Proceedings of the 7th WSEAS international conference on Engineering education. 157-162.

[20] Piattini M.G., Diaz O. (2000). Advanced Database Technology and Design, Boston: Artech House.

[21] Pujawan, K. A. H. (2018). The Development of Interactive Multimedia with Drill and Practice Model on Multimedia Ii (Two Dimension Animation) Course in Politeknik Ganesha Guru. Journal of Education Research and Evaluation, 2(1), 22-27.

[22] Rabren, J. (2010). Technology, Integration and Data Drive Supply Chain Visibility. Material Handling Management, Retrieved Business Source Complete database, 65(3), 42.

[23] Rahman, M., Abd, J., \& Ismail, M. (2014). Development and Evaluation of the Effectiveness of Computer-Assisted Physics Instruction. International Education Studies, 7(13), 14-22.

[24] Ramayah, T., Omar, R. (2010). Information Exchange and Supply Chain Performance. International Journal of Information Technology \& Decision Making, 9(01), 35-52.

[25] Schildkamp, K., Lai, M.K., \& Earl, L. (2013). Data-Based, Decision Making In Education, Challenges, and Opportunities. New York: Springer.

[26] Seow, P. S., Pan, G. (2017). Using an online tutorial to teach
REA data modeling in Accounting Information Systems courses. AIS Educator Journal, 12(1), 1-19.

[27] Setiawan, A., Ilman, B. (2012). Perencanaan Strategik Sistem Informasi pada Perusahaan Penerbitan dengan Metode Ward \& Peppard: Studi Kasus pada Penerbit Rekayasa Sains Bandung. Journal of Technology Management, 11(3), 308-324.

[28] Simarmata, J., Limbong, T., Napitupulu, E., Sriadhi, S., Tambunan, A. R. S., \& Sinaga, E. K. (2018). Learning Application of Multimedia-Based-Computer Network Using Computer Assisted Instruction Method. Int. J. Eng. Technol, 7(2.13), 341-344.

[29] Suleman, Q., Hussain, I., Din, M. N. U., \& Iqbal, K. (2017). Effects of Computer-Assisted Instruction (CAI) on Students' Academic Achievement in Physics at Secondary Level. Computer Engineering and Intelligent Systems, 8(7), 9-17.

[30] Thomas, T., Alexander, K., Jackson, R., \& Abrami, P. C. (2013). The differential effects of interactive versus didactic pedagogy using computer-assisted instruction. Journal of Educational Computing Research, 49(4), 403-436.

[31] Widayanti, I., \& Wibawa, S. C. (2016). Pengembangan Model Pembelajaran Computer Assisted Instruction (CAI) Type Tutorial Dengan Aplikasi Lectora Inspire Pada Mata Pelajaran Sistem Operasi Kelas X SMK. Journal IT-Edu, $1(2), 65-69$

[32] Yuelan, L., Yiwei, L., Yuyan, H., \& Yuefan, L. (2011). Study on Teaching Methods of Database Application Courses. Procedia Engineering, 15, 5425-5428. 